\title{
Venereal Diseases
}

In this communication the pathology, ætiology, and symptoms of cervical erosion are discussed, and there is described in detail the authors' method of treatment by electrocoagulation, which they prefer to treatment by electrocautery which may lead to subsequent dystocia or may even produce stenosis of the cervical canal. A spark-gap diathermy machine is used and only the unipolar blunt-needle electrode should be used. The method of dealing with the cervix and with the erosion is given in detail. A slough may form in the canal but drainage is established by inserting a thin applicator into the canal once a week until healing is established. Coagulation should not be undertaken ten days before or after the menstrual period, and contraindications to be kept in mind are pregnancy, acute infectiou of the cervix, and acute or subacute pelvic inflammation.

The advantages claimed for the method are that it is simple and quick; it is ambulatory and needs no hospitalization of the patient; it allows subsequent pregnancy; does not produce stenosis and, lastly, no anæsthetic is required.

The authors' technique of colour photography is described and twenty coloured photographs illustrate the types of lesion treated and the results of treatment.-ADAM BARR.

Operative Injuries of the Ureter. David Feiner (Surgery, Gyncecology, and Obstetrics, April, 1938).-Injury to the ureter is a relatively common complication of operations on the female genital organs. Various observers place the incidence of ureteral ligation as a complication in 1 to 3 per cent of all operations on the female genital organs. It is quite likely that many of the cases go unrecognized.

In this paper 8 cases are reported and the author surveys in all 710 cases. The radical abdominal hysterectomy for carcinoma of the cervix is very apt to lead to injury of the ureter. Then come such operations as vaginal and abdominal hysterectomy, and operations for the removal of intraligamentous myomas. The risk of injury is greatly increased when pelvic inflammatory disease has distorted the anatomy.

If at the time of operation it is discovered that one or both ureters have been ligated or included in a clamp, the proper treatment is to deligate or remove the clamp promptly. Ordinarily, the trauma is not sufficient to cause permanent damage but, if there is evidence that the vitality of the ureter has been so impaired that a fistula is likely to develop, immediate repair should be done, in the form of uretero-ureteral or uretero-vesical anastomosis. When both ureters have been ligated and it is not discovered until the following day or later, the condition is a serious one. In such a predicament deligation may be attempted through the original wound, but this usually proves most difficult and the best method is probably to carry out a bilateral nephrostomy. A subsequent operation for ureteral anastomosis can be done when found necessary.

-WM. S. Mack.

\section{VENEREAL DISEASES.}

Sulfanilamide in the Treatment of Urological Infection. T. M. Townsend and T. M. Mulcahy (New York State Journal of Medicine, lst June, 1938).-The authors treated 171 cases of urological infections, chiefly gonorrhcea of varying degrees of intensity and periods of infection.

The results of treatment were almost uniformly good, although the duration 


\section{Books, Pamphlets, \&c., Received}

of medication was only between five and ten days. Proof of cure was taken as absence of the gonococcus in the urethral smear even after prostatic massage and the administration of whisky. The authors urge that success depends upon the intensive administration of the drug to its therapeutic limit at the beginning of treatment, and most of their cases showed some degree of toxicity at quite an early stage of treatment.-A. Lyall.

\section{Sulphanilamide in the Treatment of Gonorrhceal Vulvo-} vaginitis. S. J. Hoffman, M. Schneider, M. L. Blatt and R. D. Herrold (Journal of the Americun Medical Association, 1938, 110, 1541).-The drug was administered to twenty-five children of 3 months to 10 years, in courses of three weeks, a week elapsing between courses. The dose was $0.05 \mathrm{gm}$. per pound, reduced after two days to $0.04 \mathrm{gm}$. and then to $0.024 \mathrm{gm}$. after 5 days. The drug was given six-hourly. Reactions were infrequent and slight. In the series of 25 cases, seven were cured in an average of 17.3 days and nine in an average of 42.9 days. Only two of the remaining nine were eured by further administration of sulphanilamide.-J. BASIL RenNiE.

\section{BOOKS, PAMPHLETS, \&c., RECEIVED}

The Handicap of Deafness, by Irene R. Ewing, M.Sc., and Alex. W. E. Ewing, M.A., Ph.D., with Illustrations. London: Longmans, Green \& Co. 1938. (12s. 6d. net.)

Can Psychology Help? by Eleanor A. Montgomery, L.R.C.P., L.R.C.S., with a Foreword by H. Crichton-Miller, M.A., M.D., M R.C.P. London: Rich \& Cowan, Limited. 1938. (3s. 6d. net.)

Psyche and the Physiologists, by Edward Guy Dru Drury, M.D., B.S.Lond., D.P.H.Durh. London: H. K. Lewis \& Co., Limited. 1938. (5s. net.)

The Clinical Examination of the Nervous System, by G. H. Monrad-Krohn, M.D., F.R.C.P. Seventh Edition with 111 Illustrations. London: H. K. Lewis \& Co., Limited. 1938. (8s. 6d. net.)

Phrenology, by J. Millott Severn, F.P.B.S. Fifty Years a Phrenologist. Published by the Author, 20 Middle Street, Brighton. Printed by the Westbourne Press, Hove. (12s. 6d.)

Physiology of the Central Nervous System and Special Senses, by L. J. Vazifdar, L.M.\&.S., F.C.P.S. Captain, A.I.R.O. Seventh Edition. Revised and Enlarged with Forty-nine Illustrations. London: H. K. Lewis \& Co. Limited. 1938. (10s. 6d. net.)

City of Aberdeen. Report by the Medical Officer of Health for the Year 1937.

On the Danger List : A Case-History, by Dr. Sandor Pender, with a Foreword by Anthony Weymouth. London: Constable \& Co., Limited. (7s. 6d.)

A Short Practice of Surgery, by Hamilton Bailey, F.R.C.S.(Eng.), and R. J. McNeill Love, M.S.Lond., F.R.C.S.Eng. Fourth Edition, with 818 illustrations of which 109 are coloured. London: H. K. Lewis \& Co., Limited, 1938. (28s. net.) 